\title{
ANALISIS PENGANGGARAN MODAL PADA PT ULTRAJAYA MILK INDUSTRY Tbk. TAHUN 2013-2017
}

\author{
Oleh : \\ Eka Lusvita Wulandari \\ elusvita88@gmail.com \\ Alumni Fakultas Ekonomi Universitas IBA Palembang \\ Lily Rahmawati Harahap \\ harahaplily@gmail.com \\ Dosen Tetap Fakultas Ekonomi Universitas IBA Palembang
}

\begin{abstract}
Capital budgeting in practice is intended to conduct an investment analysis of some available investment alternatives, and then determine or choose the most profitable investment. Inappropriateness in determining investment options will result in losses of either real losses or losses due to loss of opportunity to gain an opportunity cost that can actually be realized. The investment analysis will select the available investment opportunities, so that investment can be selected that will provide the greatest benefit of every dollar invested. Capital budgeting techniques can be analyzed by appraisal method of investment as follows: Average Rate of Return, Payback Period, Net Present Value, and Profitability Index.
\end{abstract}

Keywords : Capital Budgeting, Average Rate of Return, Payback Period, Net Present Value, and Profitability Index.

\section{PENDAHULUAN}

PT Ultrajaya Milk Industry Tbk. merupakan perusahaan yang bergerak di bidang consumer goods dengan produk-produknya yaitu susu, minuman, dan makanan dalam kemasan aseptik yang tahan lama. Perusahaan ini awalnya merupakan industri rumah tangga yang didirikan pada tahun 1958. Pada saat itu, PT Ultrajaya merupakan sebuah perusahaan susu kecil yang terletak di jalan Raya Cimareme No. 131, Padalarang, Bandung. Kemudian menjadi suatu entitas perseroan terbatas pada tanggal 2 November 1971 dengan nama PT Ultrajaya Milk Industry \& Trading Company. Perusahaan ini merupakan pionir di bidang industri minuman dalam kemasan di Indonesia, dan sekarang memiliki mesin pemroses minuman tercanggih se-Asia Tenggara.

Pada tahun 1988, PT Ultrajaya Milk Industry \& Trading Company mulai melakukan ekspansi ke luar negeri dengan mengekspor beberapa produknya. Seiring dengan perkembangan bisnis, PT Ultrajaya Milk Industry \& Trading Company berubah menjadi perusahaan public dengan melakukan listing di pasar modal Bursa Efek Jakarta (BEJ) pada tanggal 2 Juli 1990.

Hingga kini, kantor pusat dan pabrik PT. Ultrajaya tetap berlokasi di Jalan Raya Cimareme 131, Padalarang,Bandung. Pabrik ini terletak di lokasi yang strategis yaitu 
terletak di perlintasan hasil peternakan dan pertanian. Lokasi ini sangat mendukung dalam pemasokan bahan baku maupun pengiriman hasil produksi.

Produk

\section{Ultra Milk}

Ultra Milk merupakan susu kotak UHT pertama dan terpopuler di Indonesia. Ultra Milk tersedia dalam pilihan rasa:

- Ultra Milk Susu UHT Full Cream (Kotak 1 liter, 250 ml, 200ml)

- Ultra Milk Susu UHT Rasa Coklat (Kotak 1 liter, 250 ml, 200 ml, 125 ml)

- Ultra Milk Susu UHT Rasa Stroberi (Kotak 250 ml, 200 ml, 125 ml)

- Ultra Milk Susu UHT Rasa Moka (Kotak 250 ml, 200 ml)

- Ultra Milk Low Fat Hi-Calcium Full Cream (Kotak 1 liter, 250 ml, 200 ml)

- Ultra Milk Low Fat Hi-Calcium Rasa Coklat (Kotak 1 liter, 250 ml, 200 ml)

\section{Ultra Susu Kental Manis}

- Ultra SKM Full Cream

- Ultra SKM Rasa Coklat

\section{Ultra Mimi}

Ultra Mimi merupakan susu kotak UHT yang cocok untuk anak-anak. Ultra Mimi (kotak $125 \mathrm{ml}$ ) tersedia dalam pilihan rasa:

- Mimi Rasa Coklat

- Mimi Rasa Vanila

- Mimi Rasa Stroberi

\section{Teh Kotak}

Teh Kotak merupakan produk minuman teh dalam kemasan kotak pertama di Indonesia. Teh Kotak tersedia dalam pilihan kemasan:

- Teh Kotak Jasmine Tea (kotak 500 ml, 200 ml plus ekstra 100 ml)

Selain itu Teh Kotak juga mengeluarkan Teh Kotak Rasa Buah (kotak 200 ml plus ekstra $50 \mathrm{ml}$ ) yang tersedia dalam pilihan rasa:

- Teh Kotak Rasa Apel

- Teh Kotak Rasa Blackcurrant

- Teh Kotak Rasa Jambu

- Teh Kotak Rasa Jeruk

- Teh Kotak Rasa Stroberi

- Teh Kotak Rasa Lemon Madu 


\section{Kiyora}

Kiyora merupakan produk minuman teh dalam kemasan botol. Diproduksi bersama Ito En dengan Ultrajaya. Kiyora tersedia dalam pilihan rasa:

- Kiyora Teh Hijau

- Kiyora Ekstra Teh Hijau

- Kiyora Teh Susu

- Kiyora Matcha Latte

\section{Keju (kerjasama antara Kraft dan Ultrajaya)}

- Qeju

- Kraft Singles

- Kraft Cheddar

- Kraft Quick Melt

\section{Produk lain}

- Sari Asem Asli (Kotak 250ml)

- Sari Kacang Ijo (Kotak 250ml)

- Cap Sapi Krimer Kental Manis

\section{Visi Perusahaan}

Menjadi perusahaan industri makanan dan minuman yang terbaik dan terbesar di Indonesia, dengan senantiasa mengutamakan kepuasan konsumen, serta menjunjung tinggi kepercayaan para pemegang saham dan mitra kerja perusahaan.

\section{Misi Perusahaan}

Menjalankan usaha dengan dilandasi kepekaan yang tinggi untuk senantiasa berorientasi kepada pasar konsumen, dan kepekaan serta kepedulian untuk senantiasa memperhatikan lingkungan, yang dilakukan secara optimal agar dapat memberikan nilai tambah sebagai wujud pertanggung-jawaban kepada para pemegang saham.

\section{LANDASAN TEORI \\ Pengertian Penganggaran Modal}

Keputusan investasi sering disebut sebagai penganggaran modal (capital budgeting) adalah proses kegiatan yang mencakup seluruh aktivitas perencanaan penggunaan dana dengan tujuan untuk memperoleh manfaat (benefit) pada waktu yang akan datang. Menurut (Farah:2011) Penganggaran Modal (Capital Budgeting) yaitu keseluruhan proses analisis proyek-proyek yang pengembangannya diharapkan akan berlanjut lebih dari 1 tahun dan menentukan proyek mana yang akan dimasukkan dalam capital budget. 
Penganggaran modal dalam prakteknya dimaksudkan untuk mengadakan analisis investasi dari beberapa alternatif investasi yang tersedia, untuk kemudian menetapkan atau memilih investasi yang paling menguntungkan. Ketidak-tepatan dalam menetapkan pilihan investasi akan menimbulkan kerugian-kerugian baik kerugian riil ataupun kerugian karena kehilangan kesempatan untuk memperoleh manfaat yang lebih menguntungkan (opportunity cost) yang sebenarnya dapat diwujudkan. Analisis investasi akan menyeleksi kesempatan-kesempatan investasi yang ada, sehingga dapat dipilih investasi yang memberikan manfaat terbesar dari setiap rupiah dana yang diinvestasikan. Perencanaan terhadap keputusan investasi ini sangat penting karena beberapa hal (Riyanto, 2015: 120121):

1) Dana yang dikeluarkan akan terikat untuk jangka waktu yang panjang. Ini berarti bahwa perusahaan harus menunggu selama waktu yang panjang atau lama sampai keseluruhan dana yang tertanam dapat diperoleh kembali oleh perusahaan. Ini akan berpengaruh bagi penyediaan dana untuk keperluan lain.

2) Investasi dalam aktiva tetap menyangkut harapan terhadap hasil penjualan di waktu yang akan datang. Kesalahan dalam mengadakan "forecasting" akan dapat mengakibatkan adanya "over" atau "under-investment" dalam aktiva tetap. Apabila investasi dalam aktiva tetap terlalu besar melebihi daripada yang diperlukan akan memberikan beban tetap yang besar bagi perusahaan. Sebaliknya kalau jumlah investasi dalam aktiva tetap terlalu kecilakan dapat mengakibatkan kekurangan peralatan, yang ini dapat mengakibatkan perusahaan bekerja dengan harga pokok yang tinggi sehingga mengurangi daya bersaingnya atau kemungkinan lain ialah kehilangan sebagian dari pasar bagi produknya.

3) Pengeluaran dana untuk keperluan tersebut biasanya meliputi jumlah yang besar. Jumlah dana yang besar itu mungkin tidak dapat diperoleh dalam jangka waktu yang pendek atau mungkin tidak dapat diperoleh sekaligus. Berhubung dengan itu maka sebelumnya harus dibuat rencana yang hati-hati dan teliti.

4) Kesalahan dalam pengambilan keputusan mengenai pengeluaran modal tersebut akan mempunyai akibat yang panjang dan berat. Kesalahan dalam pengambilan keputusan di bidang ini tidak dapat diperbaiki tanpa adanya kerugian.

Penganggaran modal meliputi seluruh periode investasi yang mencakup pengeluaran-pengeluaran (cost) dan manfaat (benefit) yang dikuantifikasi sehingga memungkinkan untuk diadakan penilaian dan membandingkannya dengan alternatif investasi lainnya.

Menurut Eugene F.Bringham dan Michael C. Ehrhardt:

"Capital Budgeting is the decision process that man agers use to identify those projects that add to the firm's value, and as such it is perhaps the most important task faced by financial managers and their staffs".

\section{Arti Penting Penganggaran Modal}

Secara umum, capital budgeting memiliki arti penting berupa:

1. Jangka waktu tertanamnya aset yang lama membuat perusahaan perlu memikirkan sumber dana lain bagi kebutuhan yang lain. 
2. Investasi dalam aktiva tetap menyangkut dua hal:

a. BiIa investasi yang terlampau besar akibatnya adalah banyak peralatan yang tidak beroperasi.

b. Bila investasi yang terlampau kecil sehingga kekurangan peralatan akibatnya adalah perusahaan bekerja dengan harga pokok yang terlalu tinggi sehingga mengurangi daya saing.

3. Pengeluaran dana untuk keperluan tersebut biasanya meliputi jumlah yang besar yang tidak bisa diperoleh dalam jangka waktu yang pendek atau sekaligus, sehingga perlu adanya ketelitian dalam melakukan perhitungan.

4. Kesalahan dalam melakukan penghitungan berarti berakibat panjang sehingga kerugian besar pasti terjadi.

\section{Macam-Macam Keputusan Penganggaran Modal}

Pengelompokan keputusan penganggaran modal dibuat dengan maksud untuk meningkatkan kualitas pengambilan keputusan. Proses administrasi untuk menyetujui dan mengawasi keputusan penganggaran modal berbeda untuk proyek yang berbeda. Dengan melakukan pengelompokan penganggaran modal, suatu perusahaan dapat mengembangkan prosedur administrasi yang distandardisir untuk menangani kelompok usulan investasi tertentu.

Ditinjau dari aspek penghematan biaya dan peningkatan pendapatan usulan investasi dapat dikelompokkan menjadi :

1. Penggantian (Replacement), yaitu usulan investasi untuk mengganti asset yang sudah aus agar efisiensi produksi tetap dapat dipertahankan, misalnya mesin lama diganti dengan mesin baru yang lebih efisien.

2. Perluasan (Expansion), yaitu usulan investasi yang dimaksudkan untuk menambah kapasitas produksi dari lini produk yang telah ada, misalnya menambah jumlah mesin baru yang tipenya sama dengan mesin yang telah dipakai.

3. Pertumbuhan (Growth), yaitu usulan investasi untuk mengembangkan lini produk yang baru berbeda dengan lini produk yang sudah ada, misalnya mula-mula perusahaan bergerak dalam bidang produksi sepatu kemudian melakukan investasi baru di bidang restoran.

(Farah:2011) Sementara itu ditinjau dari tingkat ketergantungannya, usulan proyek investasi dapat dikelompokkan menjadi:

1. Independent project, yaitu proyek-proyek proposal yang mempunyai fungsi yang berlainan. Misalnya, di samping sistem penanganan bahn baku, perusahaan juga membutuhkan mesin pengepak hasil produksi.

2. Mutually exclusive project, yaitu proyek-proyek yang mempunyai kesempatan yang sama untuk dipilih karena fungsinya sama. Artinya, apabila suatu proyek diterima, akan menyebabkan ditolaknya proyek yang lain. Misalnya perusahaan memerlukan perbaikan dalam sistem penanganan bahan baku di pabrik, maka pekerjan tersebut dapat dilakukan dengan conveyor belt atau forklift. 


\section{Teknik Penganggaran Modal}

Teknik penganggaran modal dapat dianalisis dengan metode penilaian usul investasi seperti berikut:

1. Tingkat Pengembalian Rata-rata (Average Rate of Return)

Menurut Martono dan Harjito (2005) Metode Average Rate of Return (ARR) mengukur besarnya tingkat keuntungan dari investasi yang digunakan untuk memperoleh keuntungan tersebut. Keuntungan yang diperhitungkan adalah keuntungan bersih setelah pajak (earning after tax, EAT). Sedangkan investasi yang diperhitungkan adalah rata-rata investasi yang diperoleh dari investasi awal (jika ada) ditambah investasi akhir dibagi dua. Hasil dari ARR ini merupakan angka relatif (persentase).

$$
A R R=\frac{\text { rata-rata laba setelah } p a j a k}{\text { rata-rata investasi }} \times 100 \%
$$

Kriteria penilaian ARR :

Jika ARR > 100\%, Investasi diterima

Jika ARR $<100 \%$, Investasi Ditolak

\section{Payback Period (PP)}

Payback period adalah periode yang diperlukan untuk dapat menutup kembali pengeluaran investasi yang menggunakan aliran cash netto/proceed. Waktu yang diperlukan agar dana yang ditanam pada suatu investasi dapat diperoleh kembali seluruhnya. Rumus yang dapat digunakan adalah sebagai berikut:

$$
\text { Payback Period }=\frac{\text { Investasi }}{\text { Jumlah uang yang diterima }} \times 1 \text { tahun }
$$

Kriteria keputusan:

1. Bila periode pengembalian proyek investasi memiliki jangka waktu yang lebih singkat jika dibandingkan dengan periode pengembalian yang telah ditentukan oleh pihak manajemen perusahaan, maka proyek diterima.

2. Bila periode pengembalian proyek investasi memiliki jangka waktu yang lebih panjang jika dibandingkan dengan periode pengembalian yang telah ditentukan oleh pihak manajemen perusahaan, maka proyek ditolak.

3. Net Present Value (NPV)

Menurut Kasmir (2003:157) Net Present Value (NPV) atau nilai bersih sekarang merupakan perbandingan antara PV kas bersih dengan PV Investasi selama umur investasi. Dapat dirumuskan seperti berikut:

Apabila:

$$
N P V=\frac{P V \text { kas bersih }}{P V \text { Investasi }}
$$

NPV > 0 , investasi yang dilakukan memberikan manfaat bagi perusahaan, maka proyek bisa dijalankan. 
NPV $<0$, investasi yang dilakukan akan mengakibatkan kerugian bagi perusahaan, maka proyek ditolak.

$\mathrm{NPV}=0$, investasi yang dilakukan tidak mengakibatkan perusahaan untung ataupun rugi, maka proyek dilaksanakan atau tidak dilaksanakan tidak berpengaruh pada keuangan perusahaan.

\section{Profitability Index (PI)}

Menurut Martono dan Harjito (2005), metode Profitability Index merupakan hasil perbandingan antara nilai sekarang dari aliran kas masuk di masa yang akan datang dengan nilai investasi. Rumus yang digunakan adalah:

Dimana: $\quad$ PV = Present Value

Profitability Index $=$ PV Proceed/PV Outlays

Outlay = Jumlah uang yang dikeluarkan atau investasi

Proceeds $=$ Jumlah uang yang diterima (kas masuk)

Dengan kriteria penerimaan dan penolakan sebagai berikut:

Jika PI > 1, maka proyek diterima

Jika PI $=1$, maka tidak menjadi masalah apakah proyek diterima/ditolak

Jika PI $<1$, maka proyek ditolak.

\section{PEMBAHASAN}

\section{Perhitungan tahun 2013}

- ARR tahun $2013=\frac{\text { rata }- \text { rata laba setelah pajak }}{\text { rata-rata investasi }} \times 100 \%$

- PP tahun 2013

$$
\begin{aligned}
& =\frac{339.279 .520 .075}{112.790 .307 .259} \times 100 \%=300 \% \\
& =\frac{\text { investasi }}{\text { jumlah uang yang diterima }} \times 1 \text { tahun }
\end{aligned}
$$$$
=\frac{119.735 .695 .043}{42.531 .132 .532}=2,8 \text { tahun }
$$

- NPV tahun $2013=\frac{\text { PV kas bersih }}{\text { PV investasi }}$

$$
=\frac{75.735 .344 .928}{68.894 .854 .034}=1,1
$$

- PI tahun 2013

$$
\begin{aligned}
& =\frac{\text { PV proceed }}{\text { PV Outlays }} \\
& =\frac{42 \cdot 531 \cdot 132 \cdot 532}{119.735 \cdot 695 \cdot 043}=0,35
\end{aligned}
$$

Perhitungan tahun 2014

- $\quad$ ARR tahun 2014

$$
=\frac{\text { rata }- \text { rata laba setelah pajak }}{\text { rata }- \text { rata investasi }} \times 100 \%
$$

- PP tahun 2014

$$
\begin{aligned}
& =\frac{304.244 .167 .438}{138.425 .227 .037} \times 100 \%=225 \% \\
& =\frac{\text { investasi }}{\text { jumlah uang yang diterima }} \times 1 \text { tahun } \\
& =\frac{151.114 .759 .031}{9.204 .145 .295}=16 \text { tahun }
\end{aligned}
$$


- NPV tahun $2014=\frac{\text { PV kas bersih }}{\text { PV investasi }}$

$=\frac{122 \cdot 340 \cdot 075 \cdot 751}{151 \cdot 360 \cdot 410 \cdot 751}=0,8$

- $\quad$ PI tahun 2014

$$
\begin{aligned}
& =\frac{\text { PV proceed }}{\text { PV Outlays }} \\
& =\frac{9 \cdot 204 \cdot 145 \cdot 295}{151 \cdot 360 \cdot 410 \cdot 751}=0,06
\end{aligned}
$$

\section{Perhitungan tahun 2015}

- $\quad$ ARR tahun 2015

$=\frac{\text { rata }- \text { rata laba setelah pajak }}{\text { rata-rata investasi }} \times 100 \%$

$=\frac{403.230 .564 .620}{150.776 .154 .874} \times 100 \%=267 \%$

- PP tahun 2015

$=\frac{\text { investasi }}{\text { jumlah uang yang diterima }} \times 1$ tahun

$=\frac{150.437 \cdot 550.716}{13 \cdot 203 \cdot 700 \cdot 712}=11,4$ tahun

- NPV tahun $2015=\frac{\text { PV kas bersih }}{\text { PV investasi }}$

$=\frac{359.837 .786 .634}{283.394 .639 .131}=1,27$

- PI tahun 2015

$=\frac{\text { PV proceed }}{\text { PV Outlays }}$

$=\frac{13 \cdot 203 \cdot 700 \cdot 712}{150 \cdot 437 \cdot 550 \cdot 716}=0,08$

\section{Perhitungan tahun 2016}

- $\quad$ ARR tahun 2016

$=\frac{\text { rata }- \text { rata laba setelah pajak }}{\text { rata }- \text { rata investasi }} \times 100 \%$

- PP tahun 2016

$=\frac{616.462 .925 .386}{171.675 .204 .432} \times 100 \%=359 \%$

$=\frac{\text { investasi }}{\text { jumlah uang yang diterima }} \times 1$ tahun

$=\frac{192.912 .858 .148}{13.603 .543 .271}=14,2$ tahun

- NPV tahun $2016 \quad=\frac{\text { PV kas bersih }}{\text { PV investasi }}$

$=\frac{672 \cdot 249 \cdot 113 \cdot 314}{77 \cdot 338 \cdot 111 \cdot 138}=8,7$

- PI tahun $2016=\frac{\text { PV proceed }}{\text { PV Outlays }}$

$$
=\frac{13.603 .543 .271}{192.912 .858 .148}=0,07
$$

\section{Perhitungan tahun 2017}

- ARR tahun $2017=\frac{\text { rata }- \text { rata laba setelah pajak }}{\text { rata-rata investasi }} \times 100 \%$ 
- PP tahun 2017

$$
\begin{aligned}
& =\frac{710.753 .317 .871}{137.221 .429 .074} \times 100 \%=518 \% \\
& =\frac{\text { investasi }}{\text { jumlah uang yang diterima }} \times 1 \text { tahun }
\end{aligned}
$$$$
=\frac{81.530 .000 .000}{20.639 .000 .000}=4 \text { tahun }
$$

- NPV tahun $2017=\frac{\text { PV kas bersih }}{\text { PV investasi }}$

$$
=\frac{599.028 .000 .000}{399.687 .000 .000}=1,5
$$

- PI tahun $2017=\frac{\text { PV proceed }}{\text { PV Outlays }}$

$$
=\frac{20.639 .000 .000}{81.530 .000 .000}=0,25
$$

Untuk teknik penganggaran modal yang terdiri dari beberapa metode, maka perhitungan penganggaran modal pada PT Ultrajaya Milk Industry pada tahun 2013 hingga 2017 dapat dirangkum pada tabel berikut.

\begin{tabular}{|l|c|c|c|c|c|}
\hline \multirow{2}{*}{$\begin{array}{c}\text { Metode } \\
\text { Penilaian }\end{array}$} & \multicolumn{5}{|c|}{ Tahun } \\
\cline { 2 - 6 } & $\mathbf{2 0 1 3}$ & $\mathbf{2 0 1 4}$ & $\mathbf{2 0 1 5}$ & $\mathbf{2 0 1 6}$ & $\mathbf{2 0 1 7}$ \\
\hline ARR (\%) & 300 & 225 & 267 & 359 & 518 \\
\hline PP (thn) & 2,8 & 16 & 11,4 & 14,2 & 4 \\
\hline NPV & 1,1 & 0,8 & 1,27 & 8,7 & 1,5 \\
\hline PI & 0,35 & 0,06 & 0,08 & 0,07 & 0,25 \\
\hline
\end{tabular}

Berdasarkan hasil perhitungan tabel diatas, maka dapat dilihat bahwa persentase nilai ARR pada tahun 2013 hingga tahun 2017 persentasenya > $100 \%$, maka berdasarkan kriteria nilai proyek/investasi tersebut dapat diterima.

Apabila diukur dari metode penilaian Payback Period dari tahun 2013 hingga 2017 nilainya berkisar antara 2,8 hingga 16 tahun. Berdasarkan kriteria periode pengembalian proyek investasi atau estimasi masa manfaat ekonomis PT Ultrajaya yang lamanya antara 3 sampai 20 tahun, maka proyek investasi tersebut dapat diterima.

Sedangkan nilai NPV dari tahun 2013 hingga tahun NPV > 0 , yang artinya investasi yang dilakukan memberikan manfaat bagi perusahaan, maka proyek bisa dijalankan.

Namun apabila dilihat dari metode PI, hasil perhitungan dari tahun 2013 hingga tahun 2017 nilainya $<1$ artinya investasi tersebut ditolak atau tidak layak untuk dijalankan.

\section{KESIMPULAN DAN SARAN Kesimpulan}

Dari perhitungan teknik penganggaran modal PT Ultrajaya Milk Industry Tbk pada tahun 2013 hingga thaun 2017 maka dapat disimpulkan bahwa: 
- Persentase nilai ARR pada tahun 2013 hingga tahun 2017 persentasenya > $100 \%$, maka berdasarkan kriteria nilai proyek/investasi tersebut dapat diterima.

- Metode penilaian Payback Period dari tahun 2013 hingga 2017 nilainya berkisar antara 2,8 hingga 16 tahun, proyek investasi tersebut dapat diterima. Karena kriteria periode pengembalian proyek investasi atau estimasi masa manfaat ekonomis PT Ultrajaya yaitu antara 3 sampai 20 tahun,

- Nilai NPV dari tahun 2013 hingga tahun NPV > 0 ,yang artinya investasi yang dilakukan memberikan manfaat bagi perusahaan, maka proyek bisa dijalankan.

- Dilihat dari metode PI, hasil perhitungan dari tahun 2013 hingga tahun 2017 nilainya $<1$ artinya investasi tersebut ditolak atau tidak layak untuk dijalankan.

\section{Saran}

Penganggaran modal memiliki kriteria dalam setiap metodenya dan dalam penganggaran modal dapat terpengaruh oleh keadaan ekonomi suatu negara seperti inflasi salah satunya. Oleh karena itu, manajer dalam perusahaan harus mampu memilih dan membuat perencanaan keuangan perusahaan karena perencanaan penganggaran (seperti keputusan investasi) merupakan pedoman kerja yang memberikan manfaat bagi manajer puncak untuk meningkatkan kinerja perusahaan tersebut.

\section{DAFTAR PUSTAKA}

Bringham, Eugene F dan Joel F. Houston. 2013. Dasar-dasar manajemen Keuangan. Jilid 1 edisi 11. Jakarta:Salemba Empat.

Margaretha, Farah. 2011. Manajemen Keuangan untuk manajer nonkeuangan. Jakarta:Erlangga.

Martono dan Harjito. 2005. Manajemen Keuangan. Yogyakarta:Ekonisia.

Bursa Efek Indonesia. (2018). Laporan Keuangan \& Tahunan. Online :9/4/18. Tersedia: $\underline{w w w . i d x . c o . i d}$

Riyanto, Bambang. 2012. Dasar-dasar pembelanjaan perusahaan. Yogyakarta: BPFE 